\title{
LABORATORY STUDIES ON THE MOLLUSCICIDAL AND CERCARICIDAL ACTIVITIES OF COMMIPHORA MOLMOL.
}

\author{
Ahmed M. Masoud ${ }^{1}$, Samia M. Fawzy ${ }^{2}$ Osama M. Salama $^{3}$ \\ ' Department of Tropical Medicine, Faculty of Medicine. El-Azhar University, Cairo, \\ Egypt. \\ ${ }^{2}$ Department of Zoology, Faculty of Science, Ain Shams University, Cairo, Egypt. \\ 3Facultly of Pharmacy, Ain Shams University, Cairo, Egypt.
}

(Received : February 27, 2000)

Key words: Plant molluscicides, cercaricides, Commiphora, vector snails.

\section{ABSTRACT}

Durified oil and oleo - resin extracls of the Arabian or Somali gum Commiphora molmol (family: Burseraceae) were used as plant molluscicides against the vector snails Biomphalaria alexandrina, Bulinus truncatus and Lymnaea natalensis. The results indicated that oil extract possesses a higher molluscicidal potency than the oleo-resin. The mortality rate of exposed snails was increased by prolongation of the exposure time. The $\mathbf{L C}_{50}$ values for the oil extract against Lymnaea natalensis were quite lower than those utulized with $B$. alexandrina and $B$. iruncamis. These values were $5.4 \& 3$ ppm. for exposure periods of 24 , $48 \& 96$ hours respectively. Conversely, the oleo - resin extract showed a more pronounced cercaricidal potency than the oil. Total death of cercariae was remarked after $1 / 4 \mathrm{~h}$ of exposure to $10.5 \& 2.5 \mathrm{ppm}$.

\section{INTRODUCTION}

The transmission of schistosomiasis and fascioliasis requires vector snails as obligate intermediate hosts. Control of vector snails is, 
therefore, relevant to the control of these parasitic diseases (Liu et al., 1997).

For the control of snail-bome diseases, several synthetic compounds were developed such as copper sulfate, sodium pentachlorophenate, sulphonated hydrocarbons, tributylin fluoride. Only niclosamide (marketed as Bayluscide; Andrews et al., 1983) is widely used in control programs (Perrett and Whitfield, 1996).

On the other hand, there is probability that some resistance to niclosamide can be induced under extreme conditions of genetic selection (Sulivan et al., 1984). Therefore, the potential use of plants for the biological control of the intermediate hosts of human schistosomiasis and other snail - transmitted parasitic infections has received a considerable attention (Medina and Woudbury, 1979; Kloos and McCullough, 1985; and Kloos et al., 1985 and Perrett and Whitfield, 1996).

In Egypt, several plant species were examined as molluscicides against the intermediate hosts of Schistosoma haematobium and S.mansoni (Motawe, 1993; Ibrahim et al., 1994; El-Emam et al., 1996; Rawi et al., 1996; Shoeb et al., 1996; El Nahas, 1997; Abd - El-Megeed, 1999 and Haridy et al., 1999).

A preliminary antischistosomal screening of Commiphora molmol (Myrrh) and its derivatives was recently conducled by Masoud et al (1997) and induced this study.

Myrrh is an oleo-gum resin obtained from the stem of Commiphora molmol (Family Burseraceae) growing in north - east Africa and Arabia. The drug is chiefly collected in Somali land. It contains 7- 17 $\%$ volatile oil, $25-40 \%$ resin, $57-61 \%$ gum and some $3-4 \%$ impurities. 
Laboratory studies on the molluscicidal and cercaricidal activities of commiplsora molmol.

The objective of the present work is a laboratory evaluation of the molluscicidal and cercaricidal activities of the oil and oleo - resin extracts of Commiphora molmol.

\section{MATERIAL AND METHODS}

\section{Preparation of the aqueous emulsion}

Two extracts were tested; oleo-resin and oil extracts. $5 \mathrm{~g}$ of oil and oleo - resin extracts were separately mixed with $3 \mathrm{~g}$ of Cremophor $\mathrm{El}$, and each mixture was transferred into $\rightarrow 100 \leftarrow \mathrm{ml}$ volumetric flasks, then diluted with dechlorenated tap water, to complete the volume.

These solutions were utilized for dilution to prepare the required concentrations, where 10 snails were set in $1.0 \mathrm{~L}$ of treated dechlorinated tap water. Three replicates were held for each treatment level and for each species of snails. Cremophor El was used as control.

\section{Preparation of the control}

$3 \mathrm{~g}$ of Cremophor El were placed in a $100 \mathrm{ml}$ volumetric flask to be dissolved with dechlorinated tap water, then completed to volume where 10 snails were set to $1 \mathrm{~L}$ of dechlorinated tap water. Two replicates were held for each treatment level.

Snails

Biomphalaria alexandrina $(7.9 \mathrm{~mm}$ shell diameter), Bulinus truncatus ( $8 \mathrm{~mm}$ shell length) and Lymnaea natalensis $(8.3 \mathrm{~mm} \mathrm{sh.} 1$. were collected from irrigation canals at Abu Rawash, Giza and reared under standard laboratory conditions for an acclimatizing period. Adult snails were exposed to various concentrations of the 2 extracts of the molluscicide, ranging from 5 to $80 \mathrm{ppm}$. Mortality rate was determined after 24, 48 and 96 hours. After exposure, snails were rinsed with dechlorinated water for 30 minutes before mortality was estimated. 
Snails death was determined by lack of movement or response, when dropped in $5 \% \mathrm{NaOH}$ solution. The LC50 values for the periods of $24 \mathrm{hr}, 48 \mathrm{hr}$ and $96 \mathrm{hr}$ were estimated, using arithmetic graphic method; short- term static bioassays (Reish and Oshida, 1986).

\section{Cercariae material}

Schistosoma haematobium cercariae were obtained from experimentally infected Bulinus truncatus (snails were obtained from the Schistosome Biological Supply Program (SBSP) at Theodore Bilharz Research Institute, Imbaba). Infected snails were allowed to shed cercariae by exposing them to light at $28{ }^{\circ} \mathrm{C}$ in a small amount of dechlorinated water. The obtained cercariae were directly used in experiments. Concentrations of the 2 extracts of the plant ranging from 0.5 to $10 \mathrm{ppm}$, were used. The cercariae were transferred to small petridishes and the different concentrations were added. Microscopical observation was carried out and a cercaria was presumed dead when all motion ceased. Two replicates were run in each case. The number of dead cercariae was determined after 15,30,60 and 90 minutes of exposure. Thereafter, all exposed cercariae were counted and mortality rates were compuled after various periods of exposure. A group of cercariae was exposed to Cremophor El as a control.

\section{RESULTS}

Commiphora molmol (Myrrh) showed variable molluscicidal potency against the three snail species tested, Biomphalaria alexandrina, Bulinus truncatus and Lymnaea natalensis and this activity was more pronounced in case of the oil extract rather than the oleo-resin one.

The exposure of $B$. truncatus snails to $15 \mathrm{ppm}$ of the oleo-resin extract for 24,48 and 96 hours led to an increase in the mortality rate of snails which were totally killed at 96 hours. In case of the oil extract, 
Laboratory studies on the molluscicidal and cercaricidal activities of commiphora moimol.

snails were totally killed at the concentration of $10 \mathrm{ppm}$ after 96 hours (Fig. 1). Total death of B. alexandrina was noticed after treatment with a concentration of $15 \mathrm{ppm}$ of the oil extract (Fig. 2). L. natalensis snails were resistant to small concentrations of oleo-resin extract after 24 hours with $100 \%$ survival rate but complete mortality occurred with $20 \mathrm{ppm}$ after 48 hours. Oil extract caused death of all snails after 96 hours with a concentration of $10 \mathrm{ppm}$ (Fig. 3) The $\mathrm{Lc}_{50}$ values in L. natalensis using the oil extract were 5 and $4 \mathrm{ppm}$ for exposure periods of 24 and 48 hours respectively, while it was diminished to $3 \mathrm{ppm}$ when the exposure extended to 96 hours. These values were generally lower than those remarked in $B$. alexandrina $(15,6,3.5 \mathrm{ppm})$ and in $B$. truncatus $(8.5,7,6$ $\mathrm{ppm})$ for the same exposure periods (24, $48 \& 96$ hours) respectively (Table 1). Moreover, even low concentrations of the oil extract caused $B$. alexandrina snails to exhibit an escape behaviour, where almost all individuals remained out of water for the whole exposure period. When they were forced back into water, a sign of haemorrhage was seen in these snails, which also stopped feeding from the first day of treatment. None of the snails in the control group died or showed significant behavioral changes.

Using the extract concentrations that kill $100 \%$ of snails, total death of S. haematobrium cercariae was recorded. The oleo - resin extract showed a more pronounced cercaricidal potency than the oil one. Total death of cercariae was remarked after $1 / 4$ hour of exposure to concentrations of 10,5 and $2.5 \mathrm{ppm}$. Moreover, cercariae exposed to extract concentrations $0.5 \mathrm{ppm}$ were completely killed after 1 hour (Fig. 4).

\section{DISCUSSION}

The use of plants with molluscicidal properties may be a simple, inexpensive and appropriate technology for controlling snails of 
trematodes diseases (Domon and Hostettmann, 1984). According to the World Health Organization guidelines on plant molluscicide screening, $100 \mathrm{mg} / \mathrm{L}(\mathrm{ppm})$ or less of the plant material should kill $90 \%$ of aquatic snails exposed for 24 hours at constant water temperature (W.H.O., 1983).

B. Iruncatus and B. alexandrina seem to meet these requirements. Similar significant molluscicidal properties were previously shown by Mkoj ot al., (1989) when the plant Solanum aculeatum was tested against $B$. pfeifferi, B. globosus and $L$. natalensis. The methanolic extract of Jatropha curcas showed a level of toxicity comparable to the one considered by Duncan and Sturrock (1987) as justifying further investigation of the respective plant material $(0.002 \%$ or $20 \mathrm{ppm}$ to kill $90 \%$ of snails within 24 hours) (Liu et al., 1997).

In the present work, the feeding of the three tested species of snails was inhibited from the first day of treatment with both the oil and oleo-resin extracts of Commiphora molmol. These observations coincide with Abd El-Megeed (1999) on L. cailliaudi and the plant extract of Calendula micrantha officinalis. The above inhibitiom may be due to either that this plant contains antifeedant substance or it has hazardous effect on snail organs. Moreover, the prolonged exposure gave an increased mortality rate and this means that the active ingredient becomes slowly and continuously released from the plant extract as long as it remains in contact with water. In the present study. the oil extract showed approximately complete mortality of the three species of snails after 3 days of treatment with low and high concentrations. The molluscicidal activity of Myrth was due to a component present in the oil extract rather than the resin (Masoud et al., 1997).

Holden (1973) and Slabbert \& Morgan (1982) and many others have reported that most of the chemical pollutants and molluscicides 
Laboratory studies on the molluscicidal and cercaricidal activities of commiphora molmol.

exchange and imposing an internal hypoxis on the organism leading to death. On the other hand, Wildish et al. (1971), Alsen et al. (1973) and Werma et al. (1979) reported that some chemical substances and pesticides are characterized by their inhibitory action on acetylcholinesterase However, their studies could not establish a linear relationship between the death of organisms and the degree of enzyme inhibition. Thus the physiological events leading to death in organisms by acute exposure to lethal levels of pesticides are still not well understood.

The advantages of applying plant substances as extracts are several. These extracts are more effective to apply than unprepared ones, so more than $95 \%$ of all molluscicidal plants in laboratories and fields are used as extracts (Hostettmann and Wolfender, 1997).

In the present work, low concentrations of the oil and oleo- resin extracts of Commiphora molmol (80ppm) can induce the death of snails within 24h. However, El Emam et al., (1996) in two field trials carried out in Sharkia Governorate to control vector snails of schistosomiasis and fascioliasis using the dry powder of Anagallis arvensis latifolia, used relatively high concentrations (125 and $100 \mathrm{ppm}$ ) to indnce death of snails.

Moreover, the LC90 of the dry powder of three local plants namely Anagallis arvensis latifolia, Agave lophantha and Bassia muruicata tested by Ibrahim et al..(1994) in the laboratory against B. alexandrina snails were 50,100 , and $165 \mathrm{ppm}$. respectively.

In the present work, the oil extract of Commiphora molmol was found to possess a higher molluscicidal activity than the oleo- resin one and the LC50 values showed that Lymnaea natalensis is more sensitive to both extracts than $B$. alexandrina and B. trunacatus. 
Similary, Rawi et al., (1996) reported that the $\mathrm{LC}_{50}$ values of the crude extracts of the different parts of Calendula micrantha officinalis were more toxic than Ammi majus to B. alexandrina and B. truncatus and that the latter snail was more sensitive to the extracts of both plants than B. alexandrina.

In addition to its molluscicidal activity, Mymh has a high level of cercaricidal activity against free swimming cercariae. Oleo-resin extract was more potent than the oil. Any cercaria which is not killed by the application may be so attenuated that it becomes either unable to infect humans or fail to mature and cause significant pathology in those who they do infect (Hilal et al., 1989; Perrett et al., 1994 and Ahmed and Ramzy, 1997).

From the above results, it is obvious that Commiphora molmol is very promising to be utilized as a molluscicidal and cercaricidal agent with relativejy low effective concentrations and exposure time. On the other land, it seems to be ecologically safe, since it is known to have very low toxicity to mammals ( $3 \mathrm{~g} / \mathrm{kg}$ body weight, Masoud et al., 1997).

\section{REFERENCES}

Abd El-Megeed, K. N. (1999). Studies on the molluscicidal activity of Calendula micrantha officinalis (Compositae) on fascioliasis transmitting snails. J. Egypt. Soc. Parasitol., 29 (1): 183-192.

Ahmed, A. H. and Ramzy, R. M. R. (1997). Laboratory assessment of the molluscicidal and cercaricidal activities of the Egyptian weed, Solanum nigrum L. Ann. Trop. Med. Parasit., 91 (8): 931-937.

Alsen, C.A.; Henlinger, and Ohnesorge, F.K. (1973). Characterizations of cholinesterase of the cod (Gadus callerias) and the in vivo inhibition by praxon and tabun. Arch. toxic. 30: 263-275. 
Laboratory studies on the molluscicidal and cercaricidal activities of commiphora molmol.

Andrews, P.; Thyssen, J. and Lorke, D. (1983). The biology and toxicology of molluscicides, Bayluscide. Pharmacol. and Therap., 19: 245-295.

Domon, B. and Hostettmann, K. (1984). New saponins from Phytolacca dodecandra. Helv. Chem. Acta, 67: 1310-1319.

Duncan, J. and Sturrock, R. F. (1987). Laboratory evaluation of potential plant molluscicides. In plant molluscicides. UNDP / World Bank WHO Special Program for Research and Training in Tropical Diseases (ed. KE Mott), John Wiley, Chichester.

El-Emam, M. A.; Shoeb, H. A.; Ebid, F. A. and Refai, L. A. (1996). Snail control by Calendula micrantha officinalis. J. Egypt. Soc. Parasitol., 16 (2): 563-571.

El-Nahas, H.A. (1997). Laboratory assessment of molluscicidal activities of two local Egyptian plants Zag. J. Pharm., 6: 54-61.

Haridy, F. M.; Ibrahim, B. B.; Morsy, T. A. and El Sharkawy, L. M. A. (1999). Fascioliasis: An increasing Zoonotic disease in Egypt. J. Egypt. Soc. Parasitol., 20 (1): 35-48.

Hilal, S. H.; Aboutabl, E. A. and Yousif, F. (1989). Molluscicidal and cercaricidal properties of Anagallis arvensis L. ssp arvensis. Egypt. J. Bilh., 10 (1): 1-9.

Holden, A.V. (1973). Effects of pesticides on fish. In: Environmental Pollution by Pesticides (C.A. Edwards, ed) : 21-53. London, New yourk, Plenum press.

Hostettmann, K. and Wolfencier, J.L. (1997). The search for biologically active secondary metabolites. Pestic. Sci., 51:471-482.

Ibrahim, A.; Al-Zahaby, A.S.; Shoeb, H.; El Emam,M and AbdelKhalek, H. (1994). Molluscicidal activity of Anagallis arvensis, Agave lophantha and Bassia muricata plants against survival and fecundity of Biomphalaria alexandrina snails. Bull. Fac. Sci. Zagazig Univ., 16(2):645-662. 
Kloos, H. and McCullough, F. S. (1985). Ethiopian plants with proven and suspected molluscicidal activity: a new approach in plant evaluation. J. Trop. Med. Hyg., 88: 189-196.

Kloos, H.; Lim, K. C.: Heyneman, D. and McCullough, F. S. (1985). Preliminary screening of some Egyptian and Ethiopian plants for molluscicidal activity and observations on a possible method for natural snail control. J. Parasitol., 71:228-231.

Liu, S. Y.: Sporer. F.: Wink, M.: Jourdane, J.: Henning. R.: Li. Y. L. and Ruppel, A. (1997). Anthraquinones in Rheum palmatum and Rumex dentatus (Polygonaceae), and phorbol esters in Jatropha curcas (Euphorbiaceae) with molfuscicidal activity against the Schistosome vector snails Oncomelania, Biomphalaria and Bulinus. Trop. Med. and Int. Health, 2 (2): 179 - 188.

Masoud, A.; Salama, O.; Galal, M. and Bennet, J. (1997). "Therapeutics, Efficacy, Toxicity and Side effects of a New antischistosomal Drug Derived from Myrrh". Proceedings of Third Summer Conference of Egyptian Society of Tropical Medicine, Infectious and Parasitic Diseases (ESTIP), Alex, Egypt.

Medina, F. R. and Woodbury, R. (1979). Terrestrial plants molluscicidal to lymnaeid hosts of fascioliasis hepatica in Puerto Rico. J. Agrig. Univ. of Puerto Rico. 63: 366-376.

Mkoj. G. M.: Njunge. K.: Kimani. G.: Kqfi - Tsekpo. W.: Mungai. B. N.: Kamau. T.: Muthaura, C.: Kibava, R. M. and Wambayi, E. (1989). Molluscicidal activity of Solanum aculeatum (Family: Solanaceae) berries against Biomphalaria pfeifferi, Bulinus globosus and Lymnaca natalensis. Trop. Med. Parasit., 40: 119120.

Motawe, H. M. (1993). Effect of some plant saponins on Biomphalaria alexandrina snails. Egypt. J. Bilh., 15 (1-2): 189-193.

Perrett, S. and Whitfield, P. J. (1996). Currently available molluscicides. Parasitology Today, 12: 156-159. 
Laboratory studies on the molluscicidal and cercaricidal activities of commiphora molinol.

Perrett, S.; Whitfield, P. J.; Bartlett, A. and Sanderson, L. (1994). Attenuatiois of Schistosoma mansoni cercariae with a molluscicide derived from Millettia thonningiz. Parasitology, 109: 559-563.

Rawi, SM.; El. Gindy, H.; Abd El- Kader, A.(1996). New possible molluscicides from Calendula micrantha officinalis and Ammi majus. Molluscicidal, physiological and egg- laying effects against Biomphalaria alexandrina and Bulinus truncatus. Ecotoxicol. Environ. Saf., 35(3):261-267.

Reish, D.L. and Oshida, P.S. (1986). Manual of methods in aquatic environment research. Part 10 - Short term static bioassays.

FAO fisheries Technical Paper - 247.

Shoeb, H. A.; Refahy, L. A.; Saad, A. M. and Abd El-Motagally, M. M. (1996). Screening of some dry powdered plants against Biomphalaria alexandrina snails. Egypt. J. Bilh., 16 (1-2): 189200.

Slabbert, J.L. and Morgan, W. S.G. (1982) A Bioassay technique using Tetrahymena pyriformis for the rapid assessment of toxicants in water. Water Res., 16:517-523.

Sulivan, J. T.; Cheng, T. C. and Howland, K. H. (1984). Mitotic responses of the anterior pericardial wall of Biomphalaria glabrata (Mollusca) subjected to challenge. J. Inv. Path., 44: 114116.

Werma, S.R.; Tyagi, A.K.; Bhatnagar, M.C. and Dalela, R.C. (1979). Organophosphate poisoning to fresh water teleost Channagachua: acetyl cholinesterase inhibition. Bull. Envir . Contam. Toxic., 21: 502-506.

Wildish, D.J.; Carson, W.G.; Cunningham, T. and Lister, N.J. (1971). Toxicological effects of some organophosphate insecticides to Atlantic salmon. J. Fish, Res. Bd. Can. Manuscr. Rep., 1157:1-22. 
Table 1. Lethality $\left(\mathrm{LC}_{50}\right)$ of oil and oleo-resin extracts of Commiphora molmol oil on Bulinus truncatus, Lymnaea natalensis and Biomphalaria alexandrina snails

\begin{tabular}{|l|l|c|c|c|}
\hline \multicolumn{2}{|l|}{} & \multicolumn{3}{|c|}{ LC $_{\text {so }}$ (ppm) } \\
\hline Snail & Time & $24 \mathrm{hr}$ & $48 \mathrm{hr}$ & $96 \mathrm{hr}$ \\
\hline \multirow{3}{*}{ Bulinus truncatus } & Oleo-Resin & 14 & 12 & 4 \\
\cline { 2 - 5 } & Oil & 8.5 & 7 & 6 \\
\hline \multirow{3}{*}{ Lymnaea natalensis } & Oleo-Resin & 18.5 & 12.5 & 8 \\
\cline { 2 - 5 } & Oil & 5 & 4 & 3 \\
\hline Biomphalaria alexandrina & Oleo-Resin & 49.5 & 17.5 & 12 \\
\cline { 2 - 5 } & Oil & 15 & 6 & 3.5 \\
\hline
\end{tabular}

Table 2. Cercaricidal activity of oil and oleo-resin extracts of Commiphora molmol against Schistosoma haematobium.

\begin{tabular}{|l|c|c|c|c|c|}
\hline Extract & $\begin{array}{c}\text { Concentration } \\
\text { tested (in ppm) }\end{array}$ & \multicolumn{4}{|c|}{$\begin{array}{c}\text { Mortality rate (\%) of cercariae after } \\
\text { exposure period (in minutes) }\end{array}$} \\
\cline { 2 - 6 } & & $\mathbf{1 5}$ & $\mathbf{3 0}$ & $\mathbf{6 0}$ & $\mathbf{9 0}$ \\
\hline Oil & $0.5 \mathrm{ppm}$ & 0 & 0 & 0 & 0 \\
& 1 & 0 & 0 & 71.4 & 83.3 \\
& 2.5 & 42.5 & 11.5 & 10.0 & 100 \\
& 5 & 88.8 & 12.7 & 100 & 100 \\
& 10 & 100 & 100 & 100 & 100 \\
\hline Oleo-Resin & 0.5 & 0 & 25 & 100 & \\
& 1 & 28.5 & 100 & 100 & \\
& 2.5 & 100 & 100 & 100 & \\
& 5 & 100 & 100 & 100 & \\
& 10 & 100 & 100 & 100 & \\
\hline
\end{tabular}



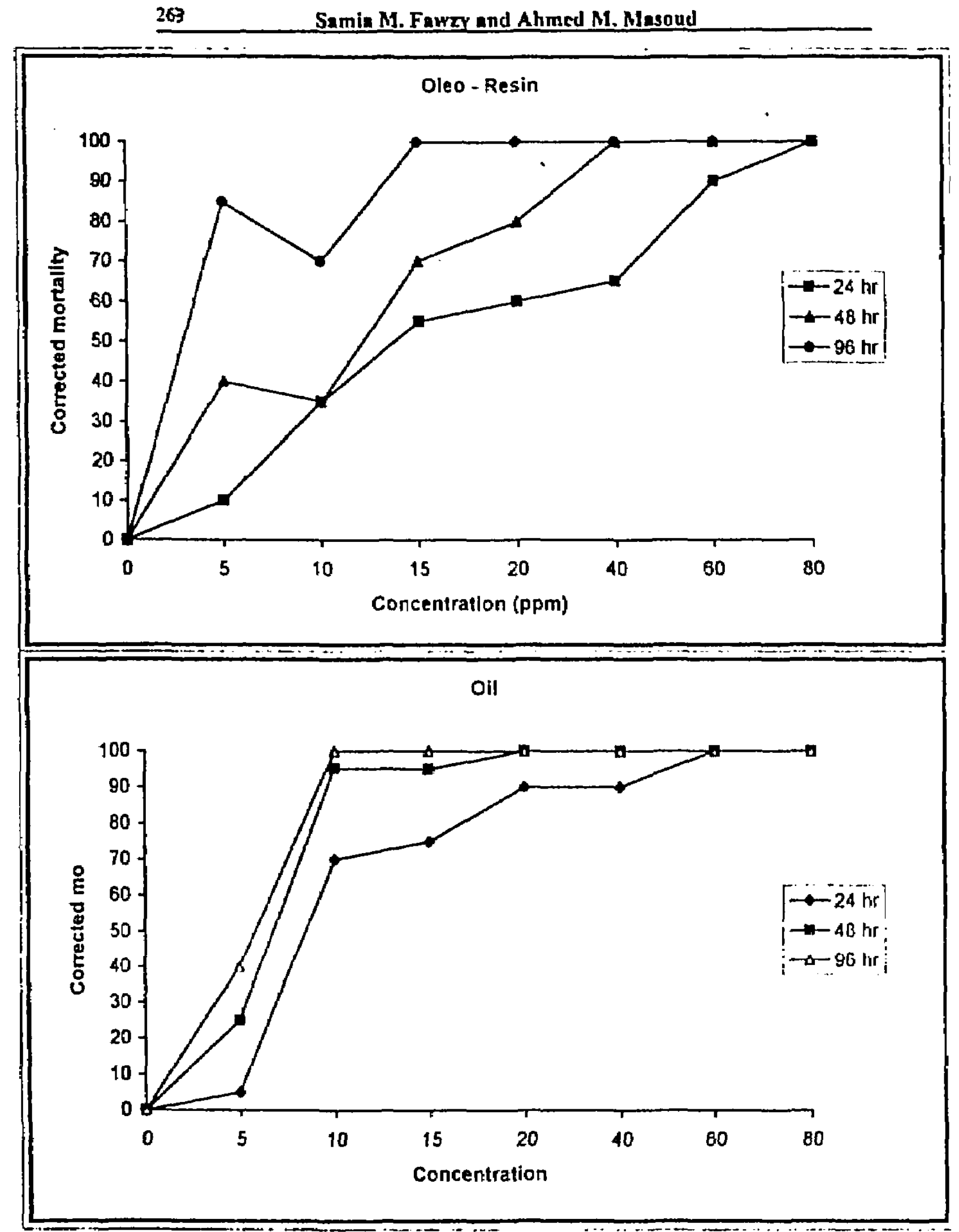

Fig. 1. Molluscicidal aclivily of oleo-resin and oil extracis of Commiphora molmol against Bulimus Iruncasus. 
Lrboratory studies on the molluscicidal and cercaricidal activities of cammiphora molmol.

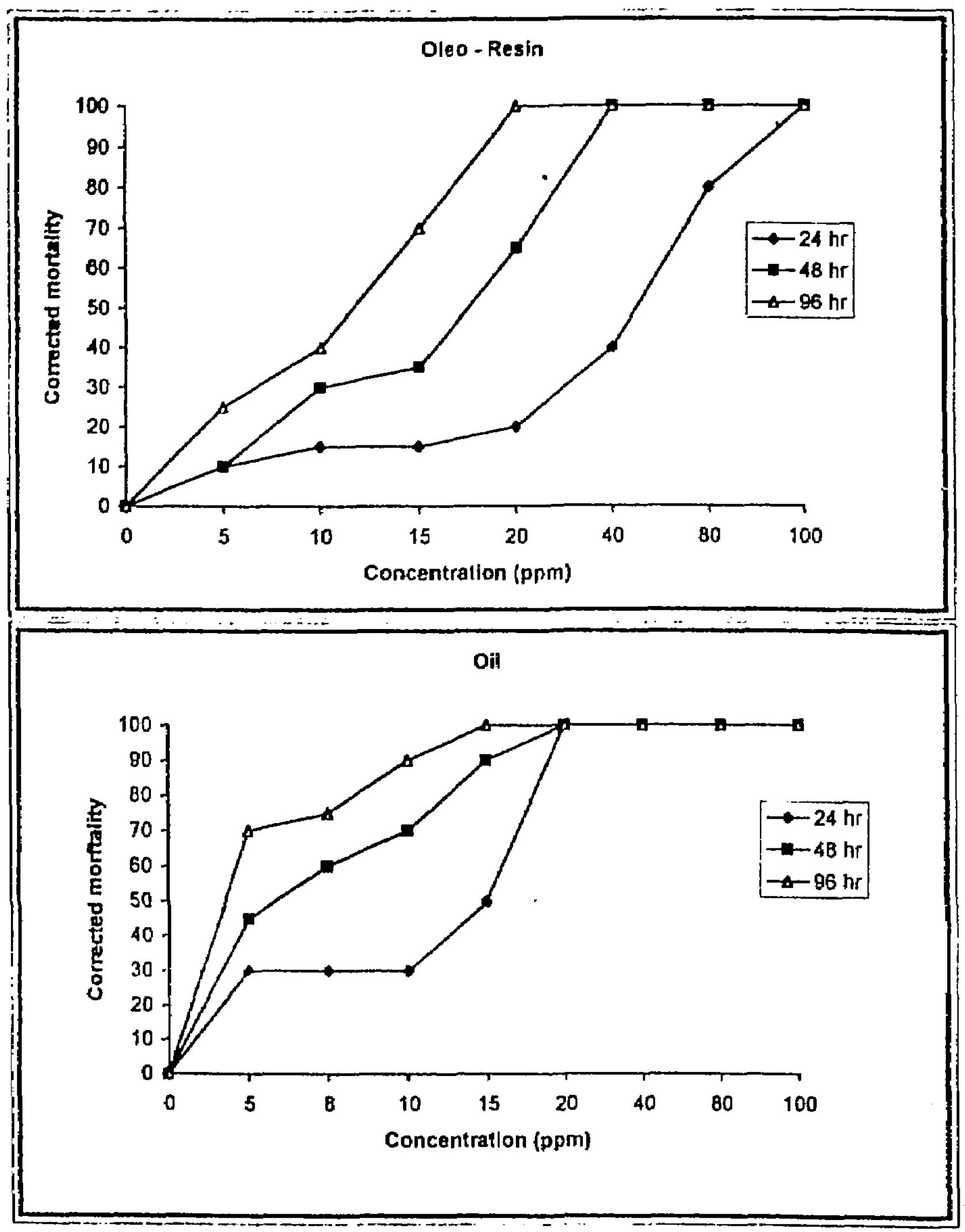

Fig. 2. Molluscicidal activity of olco-resin and oil extracts of Cummiphora molmol against Biomphalaria alexandrine. 


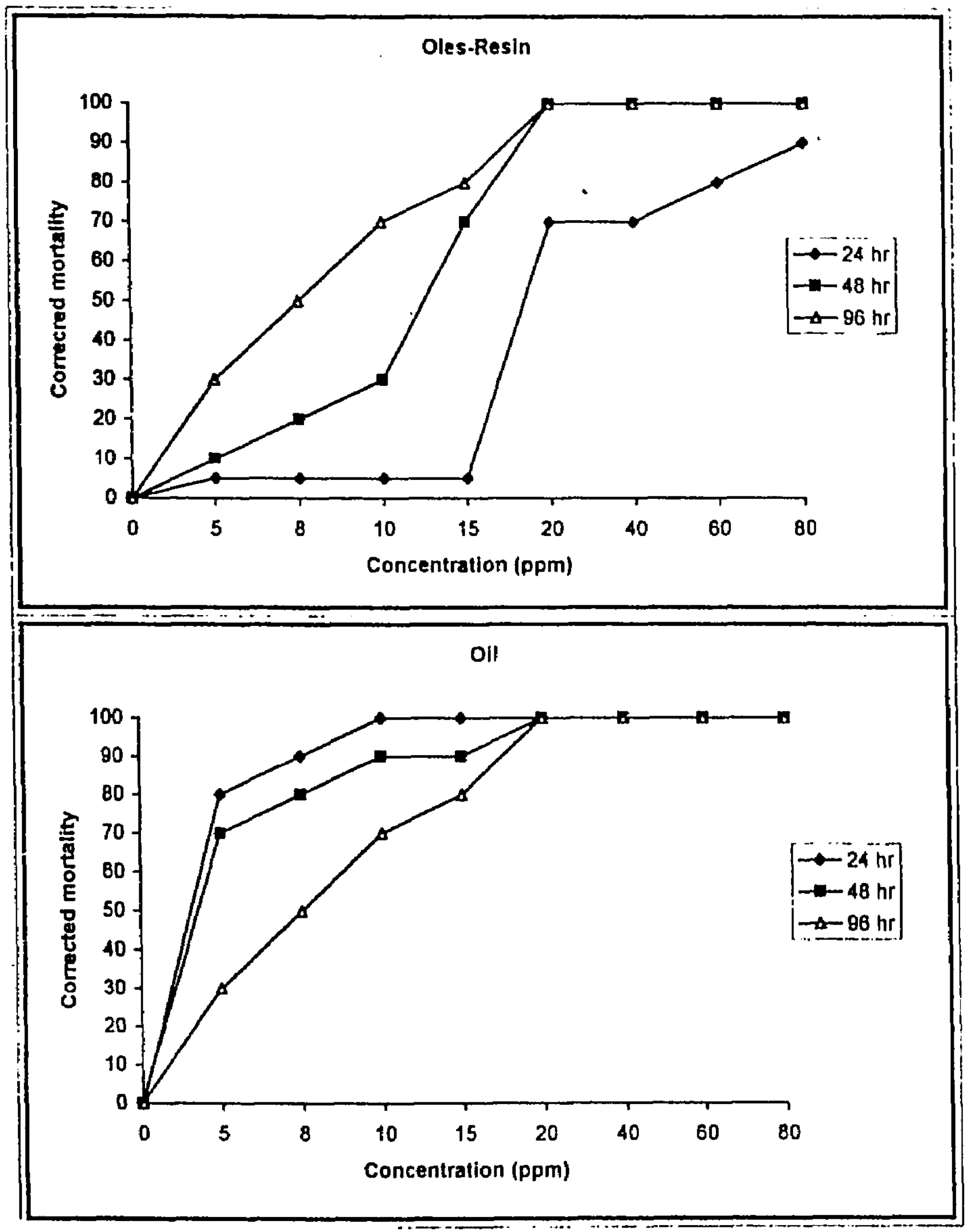

Fig. 3. Molluscicidal aclivity of oleo-resin and oil extracts of Commiphora molmol against Lymnaca nalalensis. 